WHO has come under widespread criticism for having become an unwieldy, top-heavy, bureaucratic monstrosity that does many things poorly and few things well. Calls for reform have been frequent.

In 2002, the WHO was slagged as a "bureaucracy for bureaucracy's sake, mired in useless statement-making and conference-giving" (http://reason.com /archives/2002/01/01/who-cares). The harsh editorial argued that WHO had errantly shifted away from health into the realm of politics, taking on issues such as social inequality, and that the health concerns it did address were most pertinent to richer nations, such as increasing seat belt use, at the expense of the world's poor and sick. "Since the WHO's funding is mostly from First World governments, making them its relevant 'customer base,' it caters to First World concerns. WHO's recent history has been a vivid example of bureaucratic creep. In expanding its purview far beyond merely medical, WHO is trying to stave off extinction."

In previous commentaries, $\mathrm{WHO}$ has been accused of suffering from such deficiencies as weak leadership and petty corruption (BMJ 1994;309:1424), and of being overstaffed and overcommitted (BMJ 1995;310:543-4).

Even WHO's leaders are now pointing out shortcomings. In a recent report, WHO Director-General Dr. Margaret Chan wrote that the organization has done a poor job of strategically setting priorities, is duplicating work done by other health organizations and is too rigid to rapidly adapt to challenges (http://apps.who.int/gb/ebwha/pdf_files /WHA64/A64_4-en.pdf).
"At the end of the decade, WHO finds itself overcommitted, overextended, and in need of specific reforms," wrote Chan.

To turn things around, the WHO needs to leverage its core strengths, according to a report from the Washington, DC-based Center for Strategic and International Studies (http://csis.org/files /publication/110502_Reeves_Leveraging WHO_Web.pdf). Traditionally, those strengths have been in four areas: public health surveillance, preparedness and disaster response; global standard setting and regulation; creating global partnerships to address emerging health priorities; and advocating for policy and behaviour change to combat noncommunicable diseases.

In a world of global pandemics and borderless health threats, a focused WHO is more important than ever, the report states: "Transnational disease threats of this magnitude are simply beyond the scope of a bilateral response and require the pooled resources, expertise and networks that WHO is well positioned to provide."

The WHO should also focus on solving the health problems of its member states, rather than focusing on the priorities of nations that are large donors, according to Dr. Martin McKee, professor of European public health at the London School of Hygiene \& Tropical Medicine in the United Kingdom.

"The WHO is the servant of its member states, so its priorities must reflect their priorities. However, this means that they must give it the resources to follow them through," McKee writes in an email. "WHO has two main roles, devel- oping global norms and standards and providing assistance to its member states. Unless the member states are prepared to increase their core funding, then I fear it will have to concentrate on the former, where it has no competitor, rather than the latter, where there are many other players."

WHO's budgetary allocations are "heavily skewed toward infectious diseases" McKee and others have argued (Lancet 2008;372:1563-9). In 2006-07, WHO devoted $87 \%$ of its budget to combating infectious diseases, $12 \%$ to fighting noncommunicable diseases and $1 \%$ to injuries and violence. The analysis also found that often-earmarked funding from donor nations was "misaligned with the health needs of the main recipients of the WHO's activities."

"There was closer alignment to actual burdens of diseases in the regular budget," says David Stuckler, a lecturer in sociology at the University of Cambridge in the United Kingdom, who also contributed to the budget analysis.

Glassman says WHO needs to consider a new financial model. According to one recent paper, that model should include such changes as increases to member state contributions or $20 \%-30 \%$ overheads on voluntary donations to supplement the core budget (JAMA 2011; 305:1585-6).

The organization also needs donor nations to set aside national interests. They also "need to manage their finances in a more strategic, integrated way." Roger Collier, CMAJ

CMAJ 2011. DOI:10.1503/cmaj.109-3933

\title{
Value of e-prescribing questioned
}

$\mathrm{D}$ ecades after Canada's 33700 pharmacists began buying computers in the expectation that provincial health systems would connect them with physicians through electronic prescription networks, such information sharing may be inching toward becoming a reality.

Although skeptics say the primary rationale for such networks - reduced prescription errors and expedited dispensing - may be based on exagger- ated evidence, Canada Health Infoway, the federally-funded not-for-profit organization responsible for developing electronic health records, is urging more rapid progress toward e-prescribing.

Four provinces now conform to Infoway's national technical standards for drug information systems, Kirk Ferguson, vice-president, corporate affairs, writes in an email. "Infoway achieved $98 \%$ of its target to achieve electronic capture of information from

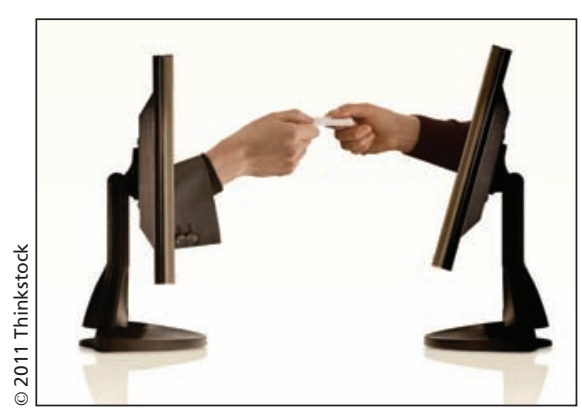

While several provinces have built centralized drug information systems that theoretically allow e-prescribing, there are few doctors in Canada who are electronically transmitting prescriptions to pharmacies. 


\section{Parsing the financial benefits of electronic health records}

The dispute over the value of e-prescribing and its effect on medication errors does not in any way appear to be unusual in the world of electronic health records.

In fact, some question all calculations of benefit accruing from such electronic records, including the benefits that Canada Health Infoway asserts have already resulted from the nation's multibillion dollar investment in the area.

An Infoway study produced in collaboration with the Toronto, Ontariobased financial consulting firm Deloitte \& Touche LLP concluded in 2010 that "Infoway-funded drug information systems" generate "\$436 million worth of annual benefits" resulting from "increased productivity of doctors and pharmacists, increased patient compliance with medications, increased patient safety and reduced preventable adverse drug events" (https://www2.infoway-inforoute.ca/Documents/DIS\%20GEN\%202\%20Study $\% 20-\% 20$ Executive $\% 20$ Summary $\% 20-\% 20$ English $\% 20$ Final.pdf).

Infoway used those numbers in the new business plan it recently prepared for Health Canada, its primary funder (https://www2.infoway-inforoute.ca /Documents/Infoway_Sum.Corp.Plan.2011-2012_EN.pdf).

But even those involved in the development of the benefits calculations says Infoway cost-savings claims may not bear scrutiny.

In the future, "it will no longer be sufficient to speculate on expected savings based on opinions of experts and extrapolation of benefits reported from a literature review," says Robyn Tamblyn, scientific director of the Canadian Institutes of Health Research's Institute of Health Services and Policy Research, chief architect of Infoway's evaluation protocols for drug information systems and a member of the expert panel that guided the Infoway/Deloitte study. The era of investment in e-health technologies "without robust evaluation is coming to an end."

Others question the way data was used, or misused, to derive the estimate of benefits.

"All of the numbers are based on literature estimates, not observed estimates," says Dr. Karim Keshavjee, a physician in Toronto, Ontario. Infoway "planners keep insisting that the benefit is from drug-drug interaction checking, but the doctors suppress more than $60 \%$ of drug-drug interaction warnings because they are spurious. Try telling that to Infoway and they'll ignore you. A big part of their business case is based on preventing drugdrug interactions."

Robert Coambs, president of Health Promotion Research, whose baseline studies were used in the Infoway/Deloitte calculations, is confounded by the handling of his data. "I am not confident about these numbers."

The estimated $\$ 436$ million in annual savings "is an extraordinary claim," Coambs adds. "And extraordinary claims require extraordinary evidence. They have not done a good job of deducing the current figures."

But Lisa Purdy, who led the Infoway/Deloitte study, says it relied on a broad spectrum of reliable data from official and public sources in Canada and abroad, including many Canadian drug information projects undertaken by Infoway. "There were over a hundred different sources of literature," she says. "No one study was weighted to be more important than any other."

Asked if there was a risk of overstatement, Purdy replied: "I wouldn't draw that same conclusion."

At a conference in Toronto earlier this year, Cassie Fraser, benefits realization leader with Infoway's Clinical Adoption Team suggested the estimate of benefits was based on "notional dollars," using a "best guess." dispensed prescriptions by the end of 2010 , and $66 \%$ of its target to provide half of Canadian pharmacies with access to patients' medication profiles by the end of 2010."

The government of Ontario was first to heed the call for more rapid progress by placing medication management and e-prescribing at the top of its list of ehealth priorities; shortlisting two information technology companies to build a province-wide e-prescribing network; and passing regulations that allow patient prescription information to move online.

Nova Scotia soon announced that it too would build an e-prescribing network, and spend $\$ 27$ million on the effort, of which $\$ 9.6$ million would be provided by Infoway.

Such high-level efforts to ensure that doctors can transfer prescriptions to pharmacists electronically are long overdue, says Janet Cooper, senior director of Professional and Membership Affairs for the Canadian Pharmacists Association.

While several provinces have built centralized drug information systems that theoretically allow e-prescribing, "in the whole of Canada there are still only a few doctors transmitting prescriptions," Cooper says, while lamenting that Infoway has concentrated on building province-wide and national integrated databases rather than simpler, cheaper local systems that simply connect pharmacists and physicians.

Even in Alberta, an e-health leader, pharmacists still rely on handwritten prescriptions and faxes from physicians that must be manually entered into the system, notes Dr. Brendan Bunting, chair of a new clinician working group that Infoway established last spring to expedite e-prescribing. "Many eHealth projects have been dogged by different design concepts, language and architecture," Bunting acknowledged in an email crafted by Infoway.

British Columbia's drug information system, meanwhile, is "vastly underutilized and is really just a viewer" for drug information, says Dr. Stephen Holland, a gastroenterologist from Victoria, who also sits on the working group. "In BC, you are still required to put a written signature on each prescription so you can't actually send it electronically. ... We have a very robust database called Phar- 
maNet in BC that's been in place longer than anywhere else in Canada. I want to see the data from PharmaNet in my electronic medical record, and then I can use that data to generate prescriptions."

But while proponents contend that eprescribing will yield faster filling of prescriptions and fewer medication errors, some Canadian researchers are skeptical.

There is little solid evidence demonstrating that e-prescribing makes a difference, says Allen Huang, associate profes- sor of medicine at McGill University in Montréal, Quebec, whose study of 28 physicians and 3400 patients found that computerization had little impact on reducing prescribing errors ( $\mathrm{J} \mathrm{Am} \mathrm{Med}$ Inform Assoc. 2008;15:430-38).

Other studies have similarly concluded that there is weak evidence that e-prescribing reduces prescription error rates (J Popul Ther Clin Pharmacol 2010;17:e243-e255 and J Eval Clin Pract 2011; doi:10.1111/j.1365-2753
.2011.01655.x.[Epub ahead of print, Mar. 18]), although the latter study found that it does increase the number of phone calls to physicians from pharmacists seeking clarification. "Physicians don't feel this has any yield," says coauthor Merrick Zwarenstein, a senior scientist at the Institute for Clinical Evaluative Sciences in Toronto, Ontario." Paul Christopher Webster, Toronto, Ont.

CMAJ 2011. DOI:10.1503/cmaj.109-3980

\section{Medical podcasts going viral}

$\mathrm{W}$ ho would have thought it possible? A podcast on gallstones or appendicitis going viral? Or at least what passes for going viral in the sequestered world known as undergraduate medical education.

Yet, a podcast produced at the faculty of medicine at the University of Alberta in Edmonton appears to be doing just that.

More than 50 episodes of "Surgery 101 " have been downloaded by students and others in 116 countries. "It took us about 16 months to get our first 100000 downloads and that was in February. And we're about to get our second 100 000 downloads and that's between February and June," says developer Dr. Jonathan White, director of surgical education at the University of Alberta.

As of late August, there were 58 episodes of Surgery 101, each offering a 10-20 minute address on a topic such as "evidence-based medicine and its use in surgery ... damage control surgery ... (and) orthopedic emergencies."

The episodes can be directly downloaded from http://surgery101.libsyn .com/ or are available for free on iTunes (http://itunes.apple.com/ca /podcast/surgery-101/id293184847). A new one is posted each Friday.

So popular is the podcast becoming that Spanish translations may be in the offing, White says, as an old colleague now working in Mexico has expressed an interest in translating the episodes into Spanish for use by people in Central and South America. It's a trend that White would like to see expanded. 'I'd like to see more initiatives like that of

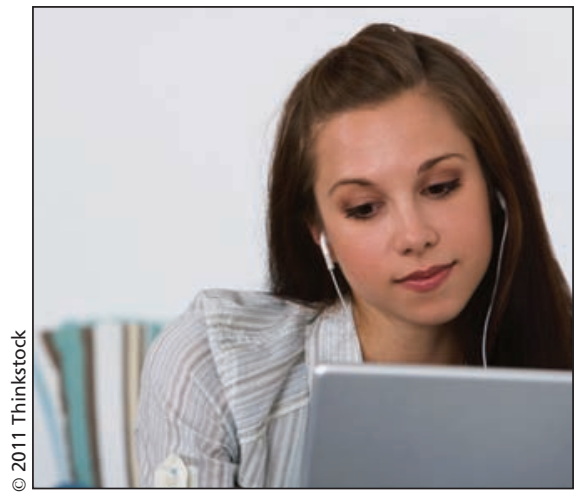

Medical students can now use online stories to obtain basic information on different surgical topics.

people making their own materials."

That would include patients and students themselves, White adds, noting that he's recently been approached by representatives of both groups inquiring as to whether they might produce new episodes from their perspective.

Patients' perspectives would be invaluable as their views are often overlooked, White says. "I think medical students sometimes get lost in the medical side of things and it's all about diseases and all that kind of stuff, and it'd be nice to hear from an actual patient who's having the surgery we're talking about or dealing with the disease we're talking about."

That the podcast is freely available is only appropriate, White says. "We're here in North America. We're in a very privileged position and we have all this expertise. I think we should give it away to people who actually need it so that's a way that our experts can actually contribute to the well-being of someone in Africa or South America. We've got our local surgeons here talking to people all across the world."

It all started in 2008 with the notion of a developing an electronic learning resource that would give students basic information on different surgical topics. White says he was long interested in using technologies as pedagogical tools. "It's a way to spread your wings and do something different as an educator."

The first episode, entitled "What is Surgery 101?" was produced in conjunction with general surgeon Dr. Parveen Boora, then a fourth-year resident who wanted to help as part of his research elective.

Boora was immediately attracted to the idea when White mentioned it in a presentation on surgical education. Under supervision, Boora recorded and edited episodes 2-10. The first was narrated by White.

"It was a project sort of intended for consumption by our med students and stuff, but we just thought we'd stick it out there for free, so it's pretty gratifying that other people find it useful," Boora says.

The first 10 episodes were put online in the fall of 2008 and the project was put on hold for a year. But it was resurrected when international interest began soaring. "We started getting emails from people we had never heard of before," White says. "People were asking when we were going to make more."

White re-initiated the project, producing some episodes on his own and calling on colleagues at the university and at Edmonton's Royal Alexandra Hospital to address such topics as coronary artery 